\title{
USING ONLINE THREADED DISCUSSIONS: BEST PRACTICES FOR THE DIGITAL LEARNER
}

\author{
DR. LISA ANNE RIZOPOULOS
}

DR. PETER MCCARTHY

Manhattan College, Riverdale, NY

\begin{abstract}
Online dialogic communities have become a ubiquitous tool that transforms student learning and course delivery. Threaded Discussions extend classroom learning by providing an asynchronous method of communication for the exchange of meaningful ideas that promote critical thinking and develop thoughtful reflective learning. Threaded Discussions transcend the physical boundaries of the classroom and capitalize on distance learning opportunities. The benefits and limitations for implementing Threaded Discussions across the content areas, along with effective strategies and practical examples, will be explored.
\end{abstract}

The digital era has brought about changes in the way students learn and dialogue with each other. Online course delivery systems, like Blackboard, have been at the forefront of this shift, and Threaded Discussions are one valuable way for students to learn and exchange ideas using technology. Threaded Discussions provide virtual learning connections which transcend class hours and provide a dynamic, dialogic learning environment where students reflect, collaborate and discuss real-world issues. This constructivist, socio-linguistic approach empowers learners to

(C) 2009, Baywood Publishing Co., Inc. doi: 10.2190/ET.39.4.c

http://baywood.com 
assume ownership of their own learning and perpetuates shared understanding and thoughtful reflection among students in a particular class or group. Specific strategies and practical examples for using Threaded Discussions for across the content area classes will be introduced and investigated.

\section{AN OVERVIEW OF THE THREADED DISCUSSION}

A thread is an online discussion that exists among students and their peers. Teachers pose questions and classmates choose to respond to each others' comments. These asynchronous conversations in the web-based discussion forum that the teacher creates for the class, catapults students into focused discussions that allow for exchanges of opinions and information. The teacher has the ability to monitor these dialogues and may even participate when needed by proposing further questions for discussion or removing potential roadblocks that inhibit the process.

\section{HOW THREADED DISCUSSIONS ARE USED}

Threaded Discussions may be used across the content areas to promote critical thinking and reflection outside of the 1-hour domain constraints of the classroom. Simply, the teacher posts an open-ended prompt that students are to react to and share with the rest of the students in the class. If the teacher prefers, students can be placed in groups according to interest or aptitude, and then appropriate groups can be formed.

\section{SETTING UP THE DISCUSSION THREAD}

The teacher sets the context for the Threaded Discussion by posting a thread, or strand, for the students to respond to. This thread strings students' ideas together based on a topic or focus chosen by the teacher. The teacher selects a topic or question that relates to the content being presented in class. This topic can extend or reinforce concepts or themes presented in class, or it can activate students' prior knowledge for the next lesson. Then, the teacher describes a suitable title for the thread that reflects the content to be presented along with a description and purpose for the forum. Directions are given to those students who are not familiar with what is expected, and a copy of the rubric is distributed to keep students focused. Directions include detailed instruction on how to participate and post messages. Students are reminded of conversation/assignment deadlines and 
links to additional resources are provided that would encourage active participation and inquiry.

Now it's time for students to begin the discussion and add a new thread. The teacher must post the initial, springboard message for students to respond to. This may come in the form of a question or prompt. It should be open-ended enough to encourage dialogue and extend conversation. It should allow students to see different perspectives and think critically about the topic.

\section{SUGGESTIONS FOR IMPLEMENTING THREADED DISCUSSIONS ACROSS THE CONTENT AREA}

Threaded Discussions can be successfully used across the content areas to foster group work and encourage higher order thinking skills. In the language arts classroom, at any grade level, it can be used to discuss and explore story grammar. For example, in the book Tuesdays with Morrie, by Mitch Albom (2002), the following quote for the story is posted for students' consideration and response: "You see, ... . you closed your eyes. That was the difference. Sometimes you cannot believe what you see, you have to believe what you feel. And if you are ever going to have people trust you, you must feel that you can trust them, too- even when you're in the dark. Even when you're falling." What does this quote mean to you? To the context of the story? How would this affect your teaching and your students' learning?

In an elementary math class, Threaded Discussions can be used to increase discourse, promote critical thinking, and reflect on mathematical reasoning. For instance, students are given a problem about money like: How many different ways can you make a dollar using four coins, two coins, one coin, ten coins, etc. ... Students can then work together to figure out the different combinations they can use to make one dollar.

Threaded Discussions can also be used to activate prior knowledge in the social studies class. In November, many social studies classes, across the grade levels, were preparing for the presidential elections. In preparation for the political debates, students can be placed in groups and asked to comment on presidential issues like the economy, the war in Iraq, abortion, foreign affairs and other pertinent topics. Students can begin to gather preliminary information about the candidate of their choice in order to effectively substantiate their position during the in-class debate. Students may even want to take this assignment a step further and suggest internet sites to be included in the Threaded Discussion resources section, pending teachers' approval.

In a secondary science class, students can be asked to complete an experiment, and at the end of the experiment, students would complete a write up and compare their findings. In a typical science class, students may be asked to discuss their hypotheses and use the internet to dissect a cow's eye online. (Wittman, n.d.). As 
each student progresses through the steps of the Scientific Method, Threaded Discussions can be used to explore observations and answer questions about the experiment, dissection.

\section{ADVANTAGES}

The advantages to using Threaded Discussions are numerous. Students have 24-hour access to their learning community. They are able to post comments whenever it is convenient for their schedule, as long as it is within the prescribed time assigned by the teacher. This is an especially convenient tool for students who work during the day and use the evening hours to complete course-related work.

In addition, students can post multiple comments and respond to their peers' comments to create an extended dialogue about a topic. They are able to read comments that may spark a different point of view and opinion about what was originally thought. For example, while reading Joey Pigza Swallowed the Key (Gantos, 1998), a story about a boy with ADHD, Perry (at 1:14 am) responded to the prompt, "Do you think Joey's teacher planned accordingly for the pumpkin picking trip? If you were Joey's teacher, how would you have handled the trip differently?" Perry replied, "Joey's mother should have been invited to the trip, so she could supervise her son. After all, she knows him the best." Christina (at 2:13 am) responded. "I didn't look at it that way. You're right. His mother knew there was going to be a trip, so she should have volunteered to chaperone." Perry (at 12:15 pm) responded, "I don't think his mother would have been able to take off from work anyway. Ultimately, it's the teacher's responsibility to take care and make provisions for the all of the students on the trip. Once the mother signed the consent form, it was the teacher's responsibility to supervise his behavior." Bryan (4:14 pm) replied, "If I were his teacher, I would have supervised him personally. He needed one-on-one attention, and the other students were fine with the chaperones. When I become a teacher, I'll make sure to personally chaperone my students with special needs, and make accommodations for them, so they can feel like they are a part of the class." This dynamic dialogic exchange shows the power of Threaded Discussion in the development of higher level thinking skills. Students synthesized the viewpoints of others by reviewing comments made to create a new idea about working with ADHD students. They constructed their own meaning, based on their life experiences and the additional information provided by their peers, as new thoughts evolved and took shape. Additionally, they personalized this information by relating it to their own knowledge, experiences, and interests about teaching and their future students.

Students' interpersonal and intrapersonal intelligence also benefits from Threaded Discussions. Intrapersonal students, those who would not regularly participate in in-class discussions, feel more confident about thinking about their responses and then commenting online. Rather than being put on the spot, these 
students will benefit from the extra time allotted for thinking about their answers, and then posting them online. This may expand both the quality and quantity of their responses, as well as their overall contribution to the community of learners. Students with interpersonal strengths view this time as a way of sharing their thoughts and feelings with their peers. They appreciate the interactive nature of the activity and build meaning as they counter in the online responsebased classroom.

Threaded Discussions also give English as a Second Language learners (ESL) an opportunity to participate in conversations that they may not have felt comfortable contributing to in class during face-to-face interactions. ESL students can be paired up with someone in the class with the same language background, and they could collaborate to create the responses in both their first language and in English. The more proficient student can translate unfamiliar words and interpret threads while both dialogue about the content. Online translation services can be used to interpret strands and prepare reflective comments. For example, students may visit Babel Fish (2008) to translate phrases or the entire threaded discussion. Babel Fish is a free online resource that translates text into more than 30 other languages within seconds. Therefore, ESL students can simply key in a phrase, and the website will create the English equivalent. Since ESL learners need extra time to process language, they can take advantage of the additional time factor allotted to complete an assignment and construct cohesive and thoughtful sentences that reflect their ideas related to the topic. Students can work at their own pace and work within their own style of learning while getting support from peers and online resources. Model postings and threads would help the ESL learner replicate the assignment requirements and can serve as a guide for their own contributions. Since paragraphs can be short and concise and bulleted information is acceptable, students can use simple sentence structure and vocabulary to communicate their ideas. One disadvantage, however, is that some ESL students prefer to speak with others' during face-to-face interactions, so they can interpret nonverbal gestures and expressions. These nonverbal cues can aid in constructing meaning and help make inferences based on facial expressions.

\section{LIMITATIONS}

One shortcoming of Threaded Discussions is that students may decide to chime in to the discussion with off topic conversation, mistaking this activity for a chat room with friends. This type of unfocused dialogue allows students to run amok if the teacher fails to set expectations, or periodically moderates/monitors the discussion. This holds students accountable for their contributions. Therefore, it is imperative for teachers to monitor the dialogue that evolves in either a synchronous or asynchronous online forum. Through modeling and by the use of illustrative examples, students can read acceptable responses from sample Threaded 
Discussions. The rubric can be created, so students can self-assess their responses before submitting them online. An example of a sample rubric can be found below.

\section{THREADED DISCUSSION RUBRIC}

The following is an example of a generic rubric that can be used to keep students on track and assess student progress while conducting Threaded Discussions. This rubric should be distributed before the Threaded Discussion assignment to ensure that students understand the requirements of the online discussion.

Introduction:

This includes clear examples of what constitutes quality contributions for this Threaded Discussion activity/assignment. Everyone should contribute in a meaningful way, adding their own ideas and perspectives.

During the discussion it is certainly acceptable to send a friendly reply to a message to let someone know that you agree with their perspective or to give someone additional information to expand the discussion parameters. However, this should be done sparingly - the discussion should not become filled with "agreement" replies that don't really add new ideas and/or perspectives to what is being presented. Remember to send a private e-mail to that person and continue the sidebar conversation.

Table 1:

Threaded Discussion Rubric

This rubric is designed to provide descriptions of what is expected of the student as the Threaded Discussion assignment is complete.

\begin{tabular}{c|c} 
Score & \multicolumn{1}{c}{ Quality of Discussion } \\
\hline 5 & $\begin{array}{l}\text { New and original ideas tangent to the discussion; insightful } \\
\text { and reflective discussion; reference to and elaboration of } \\
\text { ideas throughout the discussion; multiple contributions to } \\
\text { the discussion. }\end{array}$ \\
& $\begin{array}{l}\text { Example: } \\
\text { "I agree with Amanda in that diversity and exposure to } \\
\text { new ideas, culture, and people would be greatly enhanced. } \\
\text { However, I would like to see specific data that } \\
\text { empirically touts the efficacy of eLearning. If you did the } \\
\text { study correctly, you could measure how well eLearning } \\
\text { works. } \\
\text { Here's the key: each group will receive the exact same } \\
\text { instruction/materials/notes/lectures/etc. Even the professor } \\
\text { would be the same. Essentially, variables that could } \\
\text { potentially influence the outcome would be controlled." }\end{array}$ \\
\hline
\end{tabular}




\begin{tabular}{|c|c|}
\hline Score & Quality of Discussion \\
\hline $\begin{array}{c}4 \\
\text { Very Good }\end{array}$ & $\begin{array}{l}\text { Insightful and reflective discussion; reference to and } \\
\text { elaboration of ideas throughout the discussion; multiple } \\
\text { contributions to the discussion } \\
\text { Example: } \\
\text { "I agree with Amanda in that diversity and exposure to } \\
\text { new ideas, culture, and people would be greatly } \\
\text { enhanced. On a side note, I believe that eLearning has the } \\
\text { potential to be wonderful and bring an excellent return on } \\
\text { investment- - the key word though is potential. If all the } \\
\text { variables are not in line (i.e., enrollment, technology, } \\
\text { professor interest, tech specialists, etc.) then the } \\
\text { eLearning may fail. This is no different than traditional } \\
\text { teaching." }\end{array}$ \\
\hline $\begin{array}{c}3 \\
\text { Acceptable }\end{array}$ & $\begin{array}{l}\text { Elaboration and contribution to one idea within the } \\
\text { discussion; singular contribution to the thread } \\
\text { Example: } \\
\text { "I feel that there can be many positive advantages to } \\
\text { eLearning. } \\
\text { One advantage would be that students would have the } \\
\text { opportunity to interact with students from different parts } \\
\text { of the country and the world. This would, in turn, provide } \\
\text { diverse perspectives to the material they would be } \\
\text { learning and could open doorways they would have never } \\
\text { previously considered. }\end{array}$ \\
\hline $\begin{array}{c}2 \\
\text { Marginal }\end{array}$ & $\begin{array}{l}\text { Simple insight or contribution to the topic; single message } \\
\text { posting } \\
\text { Example } \\
\text { "As with the printing press reaching all kinds of learners } \\
\text { with whatever subject matter and information is the main } \\
\text { outcome. }\end{array}$ \\
\hline $\begin{array}{c}1 \\
\text { No Value }\end{array}$ & $\begin{array}{l}\text { "agreement" statements that merely repeat what has been } \\
\text { said by others; single message posting } \\
\text { Example } \\
\text { "I agree with what Amanda said. I think eLearning can } \\
\text { be beneficial." }\end{array}$ \\
\hline
\end{tabular}




\begin{tabular}{|c|c|}
\hline Score & Quality of Discussion \\
\hline $\begin{array}{c}0 \\
\text { (There are } \\
\text { several ways } \\
\text { to receive no } \\
\text { credit for } \\
\text { participating } \\
\text { in a } \\
\text { discussion) }\end{array}$ & $\begin{array}{l}\text { oops_didn't participate at all } \\
\text { "agreement" statements; single message posting } \\
\text { Example: } \\
\text { "Yes, I agree!" } \\
\text { "flaming" and derogatory comments to individuals } \\
\text { Example: } \\
\text { "I am tired of your longwinded responses-I don't } \\
\text { really have time to read everything you prattle on about." } \\
\text { "Yeah, well just because I don't work full time doesn't } \\
\text { mean I'm not busy—so don't tell me what to write or not } \\
\text { write." } \\
\text { messages totally unrelated to the topic of the threaded } \\
\text { discussion } \\
\text { Example: }\end{array}$ \\
\hline
\end{tabular}

Source: Nicholson, 2002.

Yet another drawback is for students with limited discourse literacy. These students have difficulty creating or sustaining an online conversation. Despite the fact that the majority of students are able to compose simple messages on the computer, many have difficulty crafting a detailed response to the prompts. Therefore, this may inhibit the student's ability to create or sustain a meaningful online conversation or limit their participation in the conversation. Perhaps these students feel more comfortable composing with the traditional pen and pencil and are reluctant to draw attention to themselves as "poor writers." One suggestion may be for these students to compose their responses on paper first, and then key in the answers during the Threaded Discussion. This would allow the students to focus on the meaning-making process; as opposed to mechanical obstacles they may face using technology. Editing tools such as spell-check and preview are available within the discussion board for reviewing the final draft. 
A suggestion for keeping students focused on using this forum in a professional manner is to give credit to students who participate in an ethical manner. This would provide positive reinforcement for those already following cyberspace rules and reinforce course standards for high expectations and professionalism.

\section{INTEGRATING FACE-TO-FACE DIALOGUE WITH ONLINE THREADED DISCUSSIONS}

Threaded Discussions can be enhanced by follow-up face-to-face discussions that take place in the classroom. In-class time is a valuable commodity, and Threaded Discussions can be used to extend face-to-face dialogue and give students additional time to reflect on issues presented. Face-to-face discussions have elements of immediacy, spontaneity, and energy that allow students to interpret their peers' voice (inflection and intonation), as well as facial expressions and body language. Therefore, these two dialogic approaches to learning can be used to complement and support each other. Before a class, Threaded Discussions can be used to activate prior knowledge and scaffolding learning and brainstorm new ideas. As a follow-up, a record of the online discussion can be shared to review and catapult new discussion. Threaded Discussions can bridge the time between classes and allow students to engage in thoughtful reflection of important themes. Since online discussion practices are less bound by time constraints, it can slow down the quick-paced nature of in-class discussions and allow ideas to ferment.

\section{THREADED DISCUSSIONS VS. OTHER METHODS OF ONLINE DISCOURSE}

Threaded Discussions, an asynchronous method of communication, differs in many ways from more synchronous methods of online communication. Asynchronous methods give additional time for students to respond and prepare their responses to threads or prompts. It also provides time to research and develop arguments before putting thoughts in print. After thoughts are committed to print, a record can be kept of the discussion. Importantly, asynchronous discussions can be used when students are not available at the same time or cannot agree on a time to participate in class dialogue or real-time conversations. Real-Time, on the other hand, allows students to see and hear each other at the same time they are speaking. However, participants must agree on a specific time to meet, and many schools may not have the technology to support Real-Time communication. Also, many students and faculty members may be unfamiliar about how to use Real-Time in their classrooms. 
Instant Messaging is yet another type of digital chat or online discussion. Instant Messaging (IM or IM-ing) is the ability to easily find out if chosen classmates, buddies who are connected to the Internet and are online at that moment. IM-ing is useful for quick questions and clarification, because it provides instant communication. However, it may not be the best option for extended responses. Some newer features include the ability to send URLs and web pages, pictures, and video. The drawbacks to using Instant Messaging include the students' use of social language. For example, students may resort to IM language like LOL (laugh out loud) and abbreviate many common words to reduce keystrokes. These shortcuts would not allow students to elaborate on responses and communicate with each other on an academic level. Another drawback may be that the students have to be online at the same time in order to speak to each other. Also, IMs need to be accepted by the receiver, therefore, restricting conversations to "buddyonly" interactions.

\section{STUDENTS' REACTIONS TO THREADED DISCUSSIONS}

During an undergraduate literacy course, pre-service teachers were asked to be a part of a literature circle based on the story The Curious Incident of the Dog in the Night-time by Mark Haddon (2003). This story, which is at an adult reading level, was shared to provide pre-service teachers with sensitivity to the unique learning requirements of autistic children. Both methods for using literature circles was used - in-class and online. Students were placed in groups of five and were asked to complete the following prompt at the conclusion of the book. Which type of dialogue format did you prefer, online or in person? Explain your rationale for your choice? Twenty-seven students replied and the data was summarized. Ninetysix percent of the students liked using Threaded Discussions. One student commented, "It was very convenient to join the group when I had time." Another participant stated, "I was able to read everyone else's comments, and then add my opinion. I waited a few minutes and checked on my group's progress again." Yet, another remark included "This was a fun and different way of conducting literature circles."

One student didn't understand how to get online to complete the activity. She asserted that she was a self-proclaimed, "computerphobe" and that she prefers working in groups in class. "I was a little frustrated, because initially I was unable to get online because of my computer. Then, I finally started entering my comments and I waited and waited for a response from my group members. I prefer face-to-face communication with my group. I enjoy that we all contribute at the same time and that we can instantaneously react to each others' comments."

Graduate education students were asked to implement various strategies in their classrooms and respond via the discussion board as to the efficacy of these tools. In keeping with best practice, this discussion forum provided a continuous bridge between graduate classes that met just once a week. 


\section{IMPLICATIONS FOR THREADED DISCUSSIONS}

Threaded Discussions provide a synergistic relationship that allows students to learn from each other and compliment each others' contributions. This article primarily focused on using Threaded Discussions as a class. However, the internet makes it possible for collaborative dialogue to extend beyond a single classroom to different schools, states, and countries. These "virtual gatherings" allow people from different locations to share ideas and data and creates a meaning-making forum for dialogue and learning. It allows experts to share their experiences with students in classes without either party traveling to the destination. Threaded Discussions trigger self-discovery and make important personal connections to content as well as to classmates. Regardless of the methodology of interaction that is employed, the teacher must design and manage these interactions to direct students in achieving the intended learning outcomes.

\section{REFERENCES}

Albom, M. (2002). Tuesdays with morrie. New York: Doubleday Books.

Babel Fish. (2008, May 8). Retrieved February 24, 2009, from Yahoo Babelfish Web site: http://babelfish.yahoo.com/

Gantos, J. (1998). Joey pigza swallowed the key. New York, NY: Harper Trophy.

Haddon, M. (2003). The curious incident of the dog in the night-time. New York: Vintage Contemporaries.

Wittman, N. (n.d.) Cow's eye dissection. [Online]. Available: http://www.exploratorium.edu/learning_studio/cow_eye/

Nicholson, M. (2002, July). Rubric evaluation for Threaded Discussions. [Online]. Available: http://iit.bloomu.edu/etraining/Discussions/discussion\%20rubric.doc

Direct reprint requests to:

Dr. Lisa Anne Rizopoulos

2 Edgemere St.

Pelham, NY 10803

Lisa.rizopoulos@manhattan.edu 
Copyright of Journal of Educational Technology Systems is the property of Baywood Publishing Company. Inc. and its content may not be copied or emailed to multiple sites or posted to a listserv without the copyright holder's express written permission. However, users may print, download, or email articles for individual use. 